\title{
Identification of a Sex Pheromone Produced by Sternal Glands in Females of the Caddisfly Molanna angustata Curtis
}

\author{
Christer Löfstedt • Jan Bergmann • Wittko Francke • \\ Erling Jirle • Bill S. Hansson • Vladimir D. Ivanov
}

Received: 14 March 2007 /Revised: 17 November 2007 / Accepted: 25 November 2007 /Published online: 23 January 2008

(C) Springer Science + Business Media, LLC 2008

\begin{abstract}
In the caddisfly Molanna angustata, females produce a sex pheromone in glands with openings on the fifth sternite. Gas chromatographic analyses of pheromone gland extracts with electroantennographic detection revealed four major compounds that stimulated male antennae. These compounds were identified by means of gas chromatography-mass spectrometry and enantioselective gas chromatography as heptan-2-one, $(S)$-heptan-2-ol, nonan-2-one, and $(S)$-nonan-2-ol in the approximate ratio of $1: 1: 4: 10$, respectively. Field tests showed that the mixture of the two alcohols was attractive to males whereas addition of the corresponding ketones reduced trap catches. The sex
\end{abstract}

C. Löfstedt $(\bowtie) \cdot$ E. Jirle $\cdot$ B. S. Hansson

Department of Ecology, Lund University,

SE-223 62 Lund, Sweden

e-mail: christer.lofstedt@ekol.lu.se

J. Bergmann • W. Francke

Institute of Organic Chemistry, University of Hamburg,

Martin-Luther-King-Platz 6,

20146 Hamburg, Germany

V. D. Ivanov

Department of Entomology, St. Petersburg State University,

199034 St. Petersburg, Russia

Present address:

J. Bergmann

Institute of Chemistry, Catholic University of Valparaíso,

Avda. Brasil 2950,

Valparaíso, Chile

Present address:

B. S. Hansson

Department of Neuroethology,

Max Planck Institute for Chemical Ecology,

Hans-Knöll-Straße 8,

07745 Jena, Germany pheromone of $M$. angustata, a species in the family Molannidae within the suborder Integripalpia, is similar to the pheromones or pheromone-like compounds previously reported from six other trichopteran families, including members of the basal suborder Annulipalpia. This suggests that minimal evolutionary change of the pheromone chemistry has taken place within the leptoceroid branch of integripalpian Trichoptera compared to the ancestral character state.

Keywords Molanna angustata $\cdot$ Molannidae $\cdot$ Trichoptera Sex pheromone $\cdot$ Nonan-2-ol $\cdot$ Heptan-2-ol $\cdot$ Nonan-2-one . Heptan-2-one

\section{Introduction}

The insect order Trichoptera (caddisflies) comprises more than 12,000 described extant species distributed among 46 families (Morse 1997, 1999, 2003). Whereas sex pheromone communication has been thoroughly investigated in the sister order Lepidoptera (moths and butterflies) and hundreds of moth sex pheromones from all of the major lepidopteran families have been identified, the corresponding information on caddisfly pheromone is limited. So far, pheromones or compounds with putative pheromonal activity have been described from only a dozen caddisfly species. Improved knowledge about sex pheromone communication in caddisflies would contribute not only to a better understanding of the reproductive biology in Trichoptera, but would also help to reconstruct the evolution of pheromone communication systems within the superorder Amphiesmenoptera that comprise the two orders already mentioned.

Pheromones occur in various evolutionary lineages of Trichoptera (Kelner-Pillault 1975; Wood and Resh 1984; 
Resh and Wood 1985; Solem 1985; Resh et al. 1987; Löfstedt et al. 1994; Bjostad et al. 1996). Attraction of males to sticky traps baited with insect extracts has established that the pheromones are produced in sternal glands situated ventrally on the fourth to fifth female abdominal segment (Resh and Wood 1985). Chemically, the trichopteran pheromones identified so far consist of short-chain secondary alcohols and the corresponding methyl ketones (Löfstedt et al. 1994; Bjostad et al. 1996). Other compounds identified from the sternum $\mathrm{V}$ glands have no known pheromonal function and may be defensive secretions rather than pheromones (Duffield et al. 1977; Ansteeg and Dettner 1991). Nevertheless, in some species, strong antennal responses to the compounds suggest that they could be pheromone components (Bergmann et al. 2001, 2002, 2004). The short-chain alcohols and corresponding methyl ketones identified from caddisflies are similar to the sex pheromone components identified from the archaic moth family Eriocraniidae (Zhu et al. 1995) and Nepticulidae (Tóth et al. 1995).

Caddisflies of the family Molannidae are advanced representatives of the leptoceroid branch within the suborder Integripalpia (Ross 1964; Weaver 1984). Field studies suggested the presence of both a swarming behavior (Solem 1984; Ivanov 1985, 1992; Solem and Petersson 1987) and female pheromone signaling (Solem and Petersson 1987) in the Molannidae, whereas no evidence for pheromone communication has been found in the family Leptoceridae, another family from the same evolutionary lineage (Petersson and Solem 1987).

Adults of the genus Molanna J. Curtis, 1834, show crepuscular activity at lakeshores. The experiments by Solem and Petersson (1987) on Molanna angustata J. Curtis, 1834, showed that whole body extracts of females attract conspecific males. The present study was performed to identify the structures of the sex pheromone components produced by female $M$. angustata and to confirm that they elicit electrophysiological responses and mediate reproductive behaviors in these insects.

\section{Methods and Materials}

Insects and Preparation of Extracts Males and females of M. angustata were collected manually or by sweep netting at lakeshores in south Sweden. The most abundant populations were found at the lakes Krageholmssjön and Snogeholmssjön situated about $60 \mathrm{~km}$ southeast of Lund. These populations were used as the source of material for chemical analyses. Only one species of Molanna occurred at these sites. Caddisflies of the genus Molanna are readily distinguishable from other local trichoptera by the shape of their wings and their pale coloration.
Adults were taken to the laboratory where females were separated from males based on their genitalia. Both sexes were placed in plastic containers with water droplets on the walls, and the containers were placed in a room with controlled climate $\left(16-20^{\circ} \mathrm{C}, 60-70 \%\right.$ relative humidity) and a reversed light/dark cycle (16L:8D) to invert the diurnal rhythm of the insects. Females spent about $40 \mathrm{~h}$ under these conditions before extraction of the pheromone glands. Early in the scotophase, insects to be dissected were freeze killed $\left(-20^{\circ} \mathrm{C}\right.$, approximately $\left.1 \mathrm{~h}\right)$ before dissection.

The fourth and fifth abdominal sternites from females were dissected and cleared from fat body components so that the glands situated in the anterodorsal part of the fifth and the posterodorsal part of the fourth sternite were exposed. Sternites with attached epithelial tissue and secretory glands were put into a micro-extraction vial that contained $100 \mu \mathrm{l}$ of dichloromethane to produce composite extracts of several females. This vial was placed in a larger screw cap vial with solvent on the bottom to saturate the atmosphere and thereby reduce the loss of solvent from the actual extract. The sample was extracted for $12 \mathrm{~h}$ at room temperature. Then, the extract was transferred to a clean micro-vial that was sealed and stored in the freezer at $-20^{\circ} \mathrm{C}$. A similar protocol was used to obtain extracts from the female abdominal tips (seventh to ninth abdominal segments), female heads, and male fourth to fifth sternites. In total, approximately $70 \mu \mathrm{l}$ of extract of fourth and fifth sternites were collected from 24 females; similar amounts of extracts were obtained from 24 female heads, 24 abdominal tips, and from 14 male fourth to fifth sternites. These extracts of females and males were analyzed by gas chromatography with electroantennographic detection (GC-EAD) and coupled gas chromatography-mass spectrometry (GC-MS). The female sternal extract was used also for field behavioral bioassays.

Electroantennography and Gas Chromatography with Electroantennographic Detection A freshly cut male antenna was placed with its basal end in a reference glass electrode that contained Beadle-Ephrussi Ringer solution (155 mM NaCl, $5 \mathrm{mM} \mathrm{KCl}, 3 \mathrm{mM} \mathrm{CaCl} 2$ ). This electrode was grounded via an $\mathrm{Ag} / \mathrm{AgCl}$ wire. The antennal tip was removed, and the apical end of the antenna was inserted into a recording electrode and connected through a Ag/ $\mathrm{AgCl}$ wire to a high-impedance DC amplifier (Syntech, Hilversum, The Netherlands) with automatic baseline drift compensation. The DC potential was recorded on a computer using an IDAC A/D converter and software (Auto Spike v. 3.0; Syntech). Filtered and humidified air continuously flowed over the mounted antenna (approximately $0.5 \mathrm{~m} / \mathrm{s}$ ). Extracts of different parts of the insect bodies were tested for electroantennography (EAG) activity by depositing one insect equivalent inside the tip of a 
Pasteur pipette and blowing $1 \mathrm{ml}$ of air through the pipette and onto the antenna.

A Hewlett-Packard 5890 Series II Plus gas chromatograph equipped with an HP Innowax column (30 $\mathrm{m} \times$ 0.25 mm i.d., Hewlett-Packard, Palo Alto, CA, USA) was used for chromatographic analyses. An effluent split allowed simultaneous flame ionization detection (FID) and EAD of the separated compounds. Hydrogen was used as carrier gas, and the effluent split ratio was approximately $1: 1$. Samples were injected splitless with injector temperature $225^{\circ} \mathrm{C}$, and the split valve was opened 1 min after injection. The column temperature was generally maintained at $40^{\circ} \mathrm{C}$ for $5 \mathrm{~min}$ after injection and then linearly increased to $230^{\circ} \mathrm{C}$ at a rate of $10^{\circ} \mathrm{C} / \mathrm{min}$. The outlet for the EAD was placed in a purified humidified air stream flowing over the antennal preparation at a speed of $0.5 \mathrm{~m} / \mathrm{s}$. Two to five microliters of an extract containing two to three female equivalents were injected onto the column for analysis.

Structure Elucidation Preliminary GC-MS analysis of active extracts was performed with a Hewlett-Packard 5890 gas chromatograph linked to a 5972 mass spectrometer and equipped with a DB-Wax $30 \mathrm{~m} \times 0.25 \mathrm{~mm}$ column (J\&W Scientific, Folsom, CA, USA), similar to the column used for GC-EAD analyses. Further analyses of the extracts were carried out by using a VG 70/70 mass spectrometer (Vacuum Generators, Manchester, UK) linked to an HP 5890GC (Hewlett-Packard) equipped with a $30 \mathrm{~m} \times$ $0.25 \mathrm{~mm}$ i.d., $0.25 \mu \mathrm{m}$ film thickness Optima 5MS column (Macherey-Nagel, Düren, Germany) or a $50 \mathrm{~m} \times 0.25 \mathrm{~mm}$ i.d., $0.25 \mu \mathrm{m}$ film FFAP column (CS Chromatographic Service, Langenwehe, Germany). Identification of volatile compounds was carried out by means of GC-MS on the basis of comparison with known mass spectra (McLafferty and Stauffer 1989) and by gas chromatographic retention times upon coinjection of natural products and synthetic reference samples. Separation of enantiomers of the chiral secondary alcohols was achieved with a $25 \mathrm{~m} \times 0.25 \mathrm{~mm}$ i.d. fused silica column coated with a 60:40 mixture of octakis-(6- $O$ methyl-2,3-di- $O$-pentyl)- $\gamma$-cyclodextrin and OV1701 (custom-made by Prof. W. A. König, Univ. Hamburg, Germany) with hydrogen or helium as carrier gas and a mass spectrometer as detector. Experimental conditions were $50^{\circ} \mathrm{C}$ for $12 \mathrm{~min}$, then to $120^{\circ} \mathrm{C}$ at $3^{\circ} \mathrm{C} / \mathrm{min}$.

Synthetic Compounds Heptan-2-one and nonan-2-one and the enantiomers of heptan-2-ol and nonan-2-ol were purchased from Aldrich. All compounds were $\geq 98 \%$ chemically pure. The optically active compounds had ee's of at least $98 \%$.

Field Trapping Attraction to extracts and synthetic compounds was examined in the field at the lake Krageholmssjön in 1996 and at the lakes Snogeholmssjön and Sövdesjön in
2004. Lund type II traps with sticky bottoms (Anderbrant et al. 1989) were distributed along the water line. Traps within a replicate (four to seven traps depending on the experiment) were placed in a group, with individual traps separated by 2-3 m distance (1996) or approximately $10 \mathrm{~m}$ distance (2004). Distances between replicates were not less than $50 \mathrm{~m}$. Traps were positioned with the bottom approximately $0.3 \mathrm{~m}$ above the water surface. Rubber septum dispensers (Arthur H. Thomas Co., $5 \times 9 \mathrm{~mm}$ red rubber septa, Catalog No. 1780-J07) were loaded with different mixtures and doses of the test compounds dissolved in dichloromethane $(500 \mu \mathrm{l}$ in 1996 and $100 \mu \mathrm{l}$ in 2004). The solvent was allowed to evaporate, and the baits were used the same day or stored in the freezer $\left(-20^{\circ} \mathrm{C}\right)$ in aluminum bags until used. The dispensers were suspended $1-2 \mathrm{~cm}$ from the trap ceiling on an insect pin.

The dose of the synthetic pheromone blends refers to the amount of the major component nonan-2-ol. Thus, a $100 \mu \mathrm{g}$ dose indicates $100 \mu \mathrm{g}$ of nonan-2-ol, and other compounds were added as required in the relative amounts in which they occurred in extracts. The blank (control) dispensers were loaded with pure dichloromethane.

Five field-trapping experiments were carried out. The first took place July 18-29, 1996 and was designed to compare the activity of different doses of two alcohols to pheromone gland extracts of females and to a synthetic four-compound blend. The alcohol lures contained a mixture of $(S)$-nonan-2-ol and $(S)$-heptan-2-ol in the proportion found in female extracts wish doses of nonan2 -ol of 10,100 , or $1,000 \mu \mathrm{g}$ per trap. The synthetic fourcompound blend contained $100 \mu \mathrm{g}(S)$-nonan-2-ol and the corresponding amounts of $(S)$-heptan-2-ol, nonan-2-one, and heptan-2-one. The pheromone extracts originated from the same sample as was used for the GC-EAD experiments, and a septum was loaded with 1.7 female equivalents.

A second experiment, similar to the first, was carried out July 29-August 10, 1996, but in this experiment, pheromone extracts were exchanged for a bait that contained ketones only. A third trapping experiment was designed to examine the effects of the individual alcohols and their corresponding $(R)$-enantiomers. The experiment was performed August 14-22, 1996. The baits tested contained the individual compounds in amounts corresponding to $100 \mu \mathrm{g}$ of nonan-2-ol. Baits were loaded with both $(S)$-alcohols, both corresponding $(R)$-alcohols, both corresponding ketones, only $(S)$-nonan-2-ol, or only $(S)$-heptan-2-ol.

A fourth experiment was carried out July 28-August 18, 2004 to confirm the attractiveness of $(S)$-nonan-2-ol and $(S)$-heptan-2-ol. Attraction to traps baited with the individual alcohols (100 and $10 \mu \mathrm{g}$, respectively, based on their relative abundance in gland extracts), and the mixture of the two compounds was examined. The final experiment was carried out August 23-September 17, 2004 to investigate 
the influence of the ratio between $(S)$-nonan-2-ol and $(S)$ heptan-2-ol. Traps were baited with $100 \mu \mathrm{g}$ of $(S)$-nonan-2ol plus different amounts of $(S)$-heptan-2-ol $(1,3,10$, and $30 \mu \mathrm{g}$ ).

Traps were checked and re-randomized every $2-4$ days during each experiment. Each reading of a trap catch was then treated as a replicate in the statistical analysis. The statistical significance of the trapping results was analyzed by generalized linear models assuming Poisson distribution and corrected for over-dispersion (SAS 9.1, proc Glimmix).

\section{Results}

EAG Recordings In preliminary tests that used insect extracts, the only distinct EAG responses recorded were those of antennae of males to extracts of females. Antennae of females were not receptive to any of the stimuli tested. Antennae of males responded strongly to extracts of the female fourth and fifth sternite, whereas head or abdominal tip extracts of females did not elicit significant EAG responses. Extracts obtained from fourth and fifth sternites of males also did not elicit any response from the antennae of males.

Gas Chromatography with Electroantennographic Detection Four EAD responses with matching peaks in the FID chromatogram (peaks 1-4) were observed consistently in the earlier part of the chromatogram during three separate analyses. In addition, in all of these analyses, three EAD responses at longer retention times (peaks 5-7) but without any visible matching FID peaks were also observed (Fig. 1). GC-EAD analyses with extracts of males and

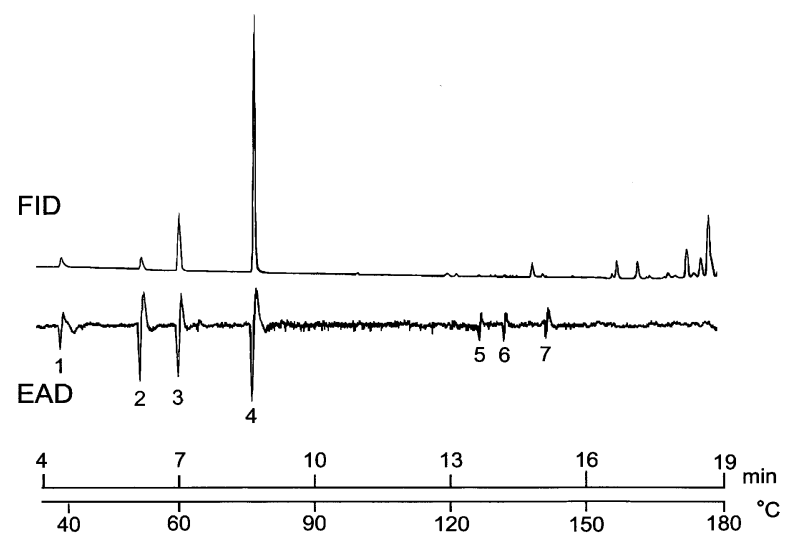

Fig. 1 Gas chromatographic analysis of an extract of female $M$. angustata fourth and fifth abdominal sternites. Simultaneous FID and EAD using a male antenna as detector. EAD-active compounds 1-4 were identified as heptan-2-one (1), (S)-heptan-2-ol (2), nonan-2-one (3), and (S)-nonan-2-ol (4) extracts from other parts of the female did not show any EAD-active peaks.

Structure Elucidation Compounds 1-4 in the extracts of sternites IV-V of females were identified as simple methylketones and the corresponding secondary alcohols. Compound 1 was identified as heptan-2-one, characterized by a weak signal for the molecular ion at $\mathrm{m} / \mathrm{z} 114$, an intense signal at $\mathrm{m} / \mathrm{z} 58$ (as a result of a McLafferty rearrangement), and a base peak at $m / z 43$ caused by $\alpha$ cleavage at the carbonyl group. Compound 2 was identified as heptan-2-ol, characterized by small signals at $\mathrm{m} / \mathrm{z} 101$ $\left(\mathrm{M}^{+}\right.$-methyl) and $m / z 98\left(\mathrm{M}^{+}\right.$-water) and a dominant base peak at $\mathrm{m} / \mathrm{z} 45$ caused by $\alpha$-cleavage at the alcohol group; the molecular ion at $\mathrm{m} / \mathrm{z} 116$ was not observed. The mass spectrometric fragmentations of the two compounds were identical with those reported in the literature (McLafferty and Stauffer 1989). The same was true for the homologs, nonan-2-one (3) and nonan-2-ol (4); the mass spectra of which showed fragmentation patterns similar to those of the C7 compounds. Diagnostic fragments were $\mathrm{M}^{+} 142$ and $m / z$ 58 as well as $m / z 43$ for the ketone, and $m / z 129\left(\mathrm{M}^{+}-15\right)$, $m / z 126\left(\mathrm{M}^{+}-18\right)$, and $m / z 45$ for the alcohol $\left(\mathrm{M}^{+}=144\right.$, was not observed).

Enantioselective gas chromatography was carried out with a modified cyclodextrin as the stationary phase and pure stereoisomers of heptan-2-ol and nonan-2-ol as references revealed the natural products to be the $(S)$ enantiomers of high stereoisomeric purity. The enantiomers of heptan-2-ol and nonan-2-ol were almost baseline separated with $\alpha=1.010-1.013$ [retention time of the later eluting $(R)$-enantiomer divided by retention time of the earlier eluting $(S)$-enantiomer] showing a valley down to $3 \%$ of the peak height. No traces of the $(R)$-enantiomers were detected in the natural products.

We were not able to identify the compounds that elicited the three EAG responses in the later part of the chromatogram (Fig. 1). None of the identified compounds were detected in extracts of males.

The amount of the major compound nonan-2-ol was estimated to be $100 \mathrm{ng}$ or more per female. Based on total ion current counts, the approximate relative amounts (within parentheses) of the four identified compounds were heptan-2-one (1), heptan-2-ol (1), nonan-2-one (4), and nonan-2-ol (10).

Field Trapping In the first of five trapping experiments, the attractiveness of a female extract was compared to three different doses of a mixture of (S)-heptan-2-ol and $(S$ )nonan-2-ol, and a mixture of the alcohols plus heptan-2-one and nonan-2-one (Fig. 2). In total, 142 males were captured in this experiment. There was no overall, statistically significant treatment effect. Numerically, the traps baited 
Fig. 2 Attraction of male $M$. angustata to female extracts, alcohols and alcohols, mixed with ketones (Experiment 1). Amounts of synthetic compounds in micrograms. $F E$ Female equivalent. Statistical significance of treatment effects (least squares means) analyzed by generalized linear model assuming Poisson error: $F_{5,52}=$ 1.04, $P=0.403$

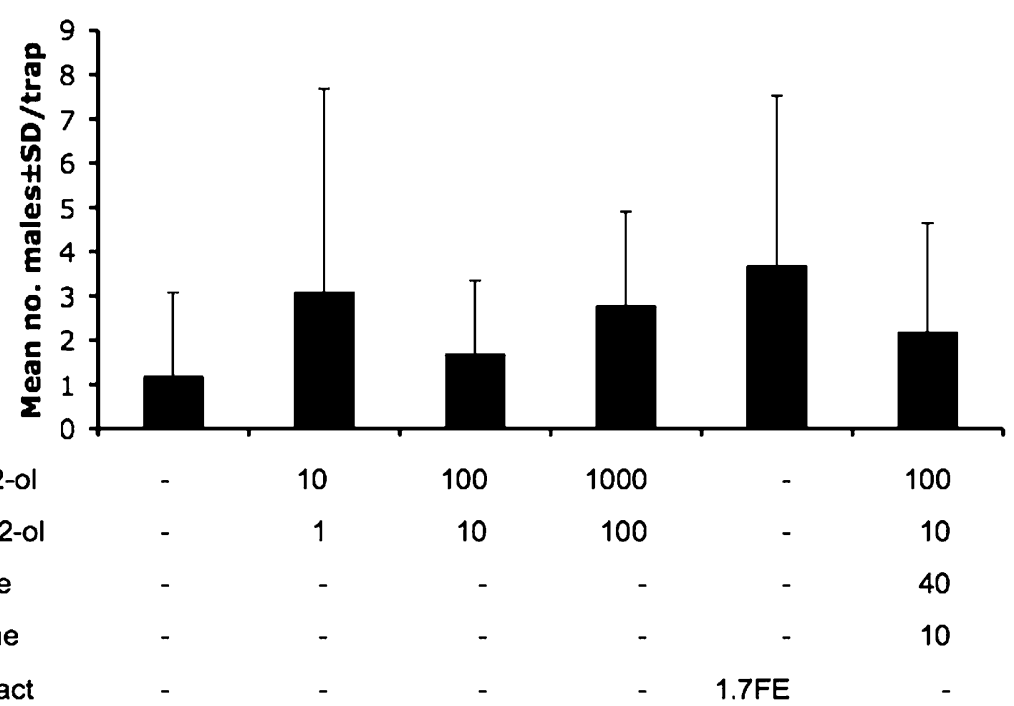

with female extracts trapped the largest number of males followed by the alcohols in the 10 and $1,000 \mu \mathrm{g}$ doses. In the second experiment (Fig. 3), the same synthetic baits and an additional bait that contained only the two ketones were tested. In this experiment, we observed a significant overall treatment effect. The three alcohol baits followed by the mixture of alcohols and ketones were the most attractive ones, significantly different from the control and the mixture of the ketones.

In experiment 3 (Fig. 4), the activities of (S)-heptan-2-ol and $(S)$-nonan-2-ol as single components were compared with the activity of the mixture of these two compounds, the activity of the mixture of the corresponding $(R)$ enantiomers, and the activity of the mixture of heptan-2one and nonan-2-one. The overall effect was statistically significant, and the mixture of the $(S)$ alcohols and $(S)$ nonan-2-ol on its own were more attractive than $(S)$-heptan2-ol, the mixture of the ketones, or the mixture of the $(R)$ alcohols. Numerically, the alcohols showed the highest trap catches, but when tested for statistical significance, all treatments were not different from the blank.

Thus, high variation in trap catches confounded the results in experiments $1-3$, carried out during the first field season. Only a few significant differences were found by using pairwise comparisons, and no pronounced differences were found between different baits or between baited traps and the control. Thus, we decided to perform two additional experiments several years later. Experiment 4 (Fig. 5) conclusively demonstrated that the mixture of $(S)$-heptan-2ol and $(S)$-nonan-2-ol in their natural ratio was significantly attractive to male $M$. angustata. Traps baited with $(S)$ nonan-2-ol as a single component gave the second highest trap catch, but this treatment was not significantly different from the results obtained with $(S)$-heptan-2-ol $(P=0.09)$ or the control. The final experiment (Fig. 6) demonstrated a significant effect of the relative amount of $(S)$-heptan-2-ol
Fig. 3 Field trapping of $M$. angustata, comparing attractiveness of alcohols, ketones, and alcohols mixed with ketones (Experiment 2). Statistical significance of treatment effects (least squares means) analyzed by generalized linear model assuming Poisson error: $F_{5,54}=$ 2.98, $P=0.019$. Values followed by the same letter are not significantly different $(P>0.05)$

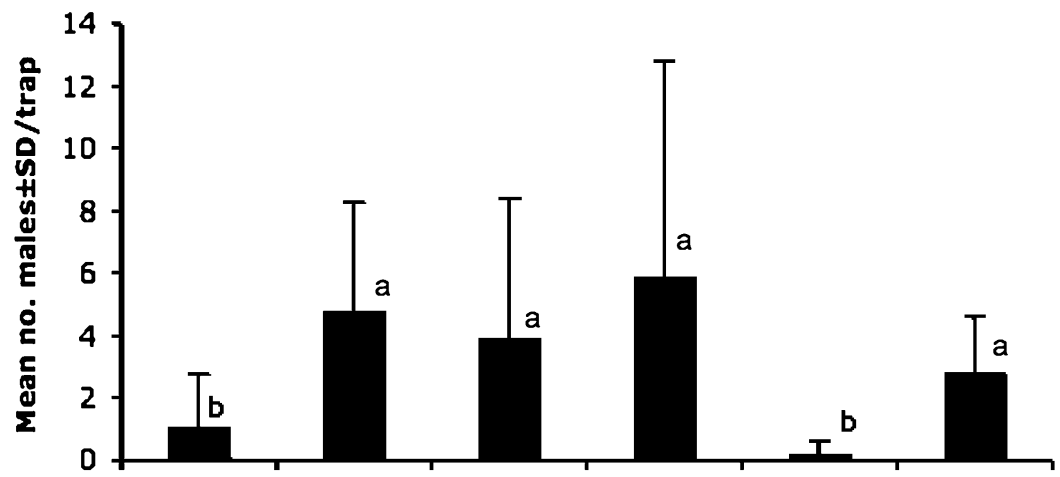

\begin{tabular}{|c|c|c|c|c|c|}
\hline (S)-Nonan-2-ol & - & 10 & 100 & 1000 & - \\
\hline (S)-Heptan-2-ol & - & 1 & 10 & 100 & - \\
\hline Nonan-2-one & - & - & - & - & 400 \\
\hline Heptan-2-one & - & - & - & - & 100 \\
\hline
\end{tabular}


Fig. 4 Field trapping of $M$. angustata, comparing attractiveness of different alcohol baits and a mixture of ketones (Experiment 3). Statistical significance of treatment effects (least squares means) analyzed by generalized linear model assuming Poisson error: $F_{5,84}=$ 2.93, $P=0.017$. Values followed by the same letter are not significantly different $(P>0.05)$

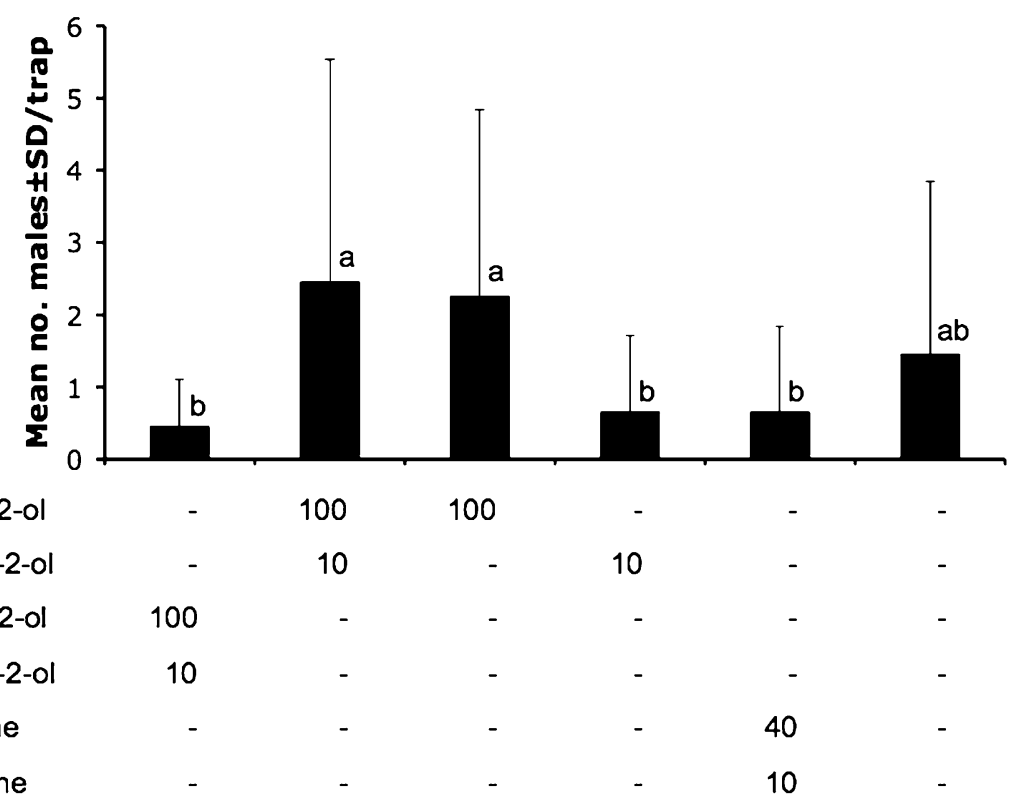

We experienced problems in our studies of pheromone communication in $M$. angustata, similar to those reported in studies of other species of caddisflies. For example, (Löfstedt et al. 1994) obtained unexpectedly high catches in unbaited control traps, whereas catches in traps baited with synthetic pheromone or insect extracts were relatively low, albeit still significantly higher than in the controls. In many other species of caddisflies, we have identified pheromone component candidates with high electrophysiological activity but have failed to demonstrate any attraction to these compounds in field trapping experiments (J. Bergmann, W. Francke, V. D. Ivanov, and C. Löfstedt, unpublished). In contrast, in trapping experiments with similar compounds that target primitive moths, large numbers of moths were attracted, and unbaited traps never trapped more than a few insects, if any (Zhu et al. 1995; Kozlov et al. 1996). This suggests that the problem is not a general technical one, related to solvent
Fig. 5 Field trapping of $M$. angustata, comparing attractiveness of $(S)$-heptan-2-ol,

$(S)$-nonan-2-ol, and their mixture (Experiment 4). Statistical significance of treatment effects (least squares means) analyzed by generalized linear model assuming Poisson error: $F_{3,54}=10.06, P<0.001$. Values followed by the same letter are not significantly different $(P>0.05)$

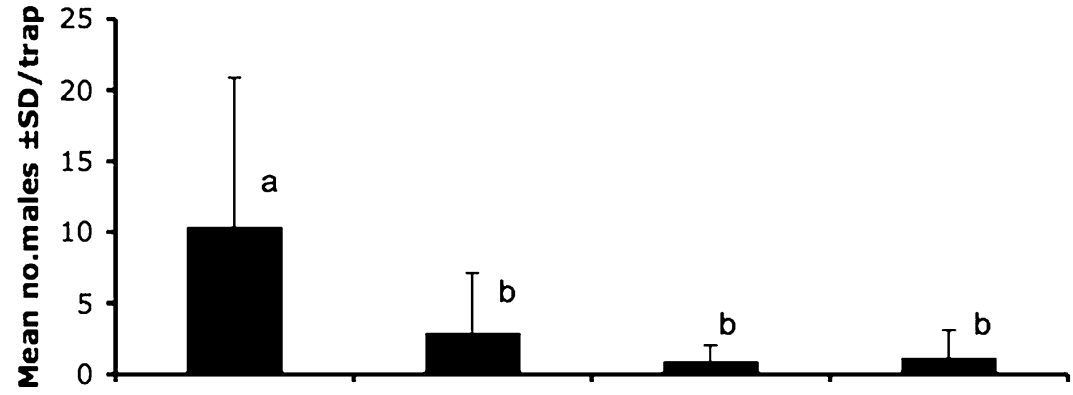

(S)-Nonan-2-ol 100

(S)-Heptan-2-ol 10 100 $\begin{array}{ll}- & 10\end{array}$ 
Fig. 6 Field trapping of $M$. angustata, comparing different amounts of $(S)$-heptan-2-ol added to $(S)$-nonan-2-ol (Experiment 5). Statistical significance of treatment effects (least squares means) analyzed by generalized linear model assuming Poisson error: $F_{3,73}=$ 2.83, $P=0.044$. Values followed by the same letter are not significantly different $(P>0.05)$

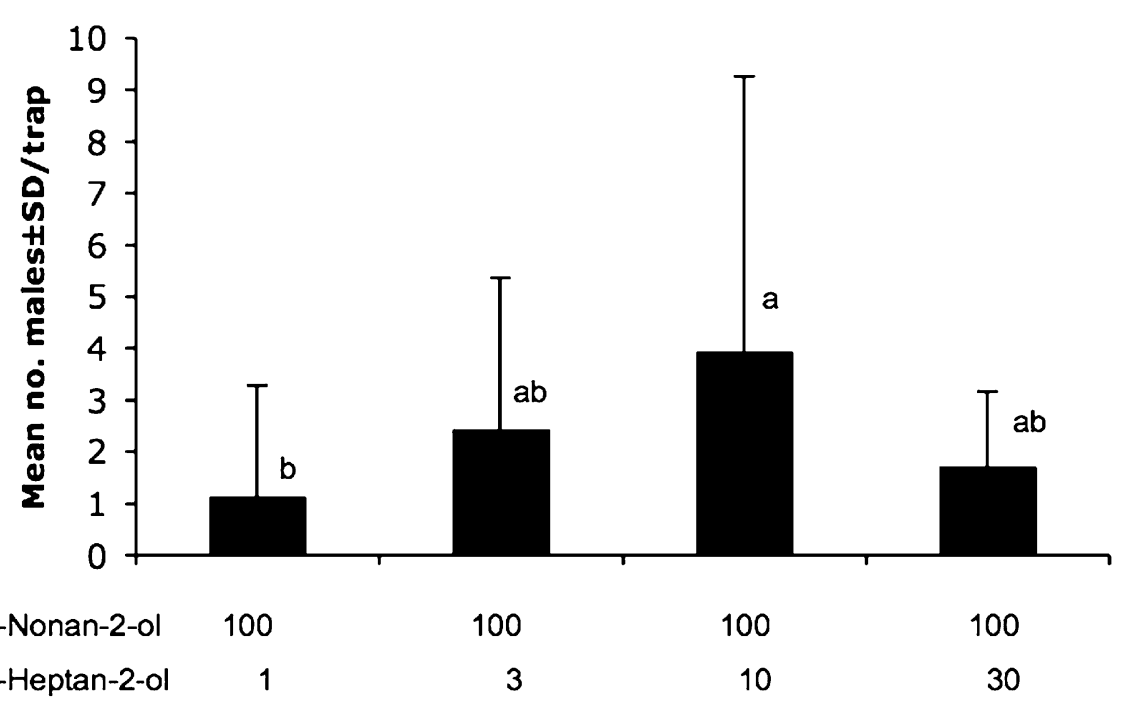

represent biologically active trace components of the pheromone blend.

The four compounds that we identified from $M$. angustata females have been identified previously from several other caddisflies (Duffield 1981; Löfstedt et al. 1994; Bergmann et al. 2002). In Rhyacophila fasciata, a mixture of the racemates of heptan-2-ol and nonan-2-ol was attractive to males (Löfstedt et al. 1994). The enantiomeric composition of female extracts was not investigated, and the enantiomers were not tested in trapping experiments. In R. nubila, males have antennal receptors specific for the enantiomers of heptan-2-ol (Larsson and Hansson 1998), and male eriocraniid moths likewise have specific receptors for $(R)$ - and $(S)$-enantiomers of methyl carbinols that have been identified as pheromone components in this moth genus (Zhu et al. 1995; Kozlov et al. 1996; Larsson et al. 2002). Females of $R$. nubila produce $(R)$-heptan-2-ol and (R)-nonan-2-ol of $99.5 \%$ ee and $90 \%$ ee, respectively (J. Bergmann, W. Francke, C. Löfstedt, and P. Valeur, unpublished). It is interesting to note that unbranched methylketones and the corresponding alcohols are widespread among Hymenoptera and that those methyl carbinols are components of the sex pheromone of the stingless eusocial bee Scaptotrigona postica (Engels et al. 1990, 1997). In Trichoptera, different combinations of alcohols and ketones or, similar to Lepidoptera and Coleoptera (Francke and Schulz 1999), the enantiomeric composition of chiral pheromone components may account for the species specificity of caddisfly pheromones. Caddisflies also use vibrational and acoustic signals for communication (Ivanov 1993, 1994), which may contribute to the species specificity of the communication systems. These signals have not been recorded for $M$. angustata, and the specific sternal structures that usually produce these signals are not present in this species. Males have been shown to perform 
the zigzagging flight similar to that of searching moths and resembling the swarming flight of Leptoceridae (Ivanov 1985), with the exception that the Molanna males never form swarms, even at high population densities.

Three suborders are recognized within the Trichoptera. Annulipalpia is concluded to be the most basal suborder, and Spicipalpia and Integripalpia form a clade (Kjer et al. 2002). Both Annulipalpia and Integripalpia are monophyletic, but whether or not Spicipalpia is monophyletic remains equivocal. Methyl carbinols and methylketones, similar or identical to those found in M. angustata, have been reported in the families Philopotamidae, Polycentropodidae, and Hydropsychidae that belong to the Annulipalpia, as well as in Rhyacophilidae and Glossosomatidae that belong to the Spicipalpia. In addition to their occurrence in the Molannidae, such compounds also have been found in Phrygaenidae belonging to a different branch within the Integripalpia (Löfstedt et al. 1994, Bergmann et al. 2002). Thus, this type of pheromone component produced in the sternum $\mathrm{V}$ gland may be a basal character in both Trichoptera and Lepidoptera and, thus, of the superorder Amphiesmenoptera (Löfstedt and Kozlov 1996), a conclusion further corroborated by the present study. The alcohols and ketones produced by females were not found in extracts of male $M$. angustata, which resembles the typical situation in Lepidoptera. In contrast, most other species of caddisflies studied previously have male-produced pheromone-like compounds similar to those found in conspecific females (Löfstedt et al. 1994; Bergmann et al. 2002, 2004) that elicit electrophysiological responses from antennae of both females and males.

Acknowledgments Karin Johnson and Dr. Mattias Larsson helped in the initial field tests of the pheromone blends and also in the collection of insects for the pheromone extractions. Valuable suggestions by Peter Valeur and Dainius Plepys are acknowledged. Henrik Smith assisted with the statistical analysis. Funding for this project was obtained from the Swedish Research Council (NFR/VR), the Royal Swedish Academy of Sciences, the Swedish Institute and the Russian Foundation for Fundamental Studies (grant No. 97-0449957). WF thanks the Fonds der chemischen Industrie, Germany, for financial support.

\section{References}

ANDERBRANT, O., LÖFQVIST, J., JÖNSSON, J., and MARLING, E. 1989. Effects of pheromone trap type, position and colour on the catch of the pine sawfly Neodiprion sertifer (Geoff.) Hym., Diprionidae. J. Appl. Entomol. 107:365-369.

Ansteeg, O., and Dettner, K. 1991. Chemistry and possible biological significance of secretions from a gland discharging at the 5th abdominal sternite of adult caddisflies (Trichoptera). Entomol. Gen. 15:303-312.

BergmanN, J., LÖFSTEDT, C., IVANOV, V. D., and FranCKe, W. 2001. Identification and assignment of absolute configuration of methyl-branched ketones from limnephilid caddisflies. Eur. J. Org. Chem. 16:3175-3179.

Bergmann, J., Löfstedt, C., IVAnov, V. D., and FrancKe, W. 2002. Electrophysiologically active volatile compounds from six species of caddisflies. Nova Suppl. Ent. 15:37-46.

BergmanN, J., LÖFSTEDT, C., IVANOV, V. D., and FranCKe, W. 2004. Identification and synthesis of new bicyclic acetals from caddisflies (Trichoptera). Tetrahedron Lett. 45:3669-3672.

Bjostad, L. B., Jewett, D. K., and Brigham, D. L. 1996. Sex pheromone of caddisfly Hesperophylax occidentalis (Banks) (Trichoptera: Limnephilidae). J. Chem. Ecol. 22:103-121.

DufFIELD, R. M. 1981. Nonan-2-ol in the exocrine secretion of the nearctic caddisfly, Rhyacophila fuscula (Walker) (Rhyacophilidae: Trichoptera). Proc. Entomol. Soc. Wash. 83:60-63.

Duffield, R. M., Blum, M. S., Wallace, J. B., Lloyd, H. A., and REGNIER, F. E. 1977. Chemistry of the defense secretion of the caddisfly Pycnopsyche scabripennis (Trichoptera: Limnephilidae). J. Chem. Ecol. 3:649-656.

ENGELS, W., Engels, E., LÜBKE, G., SchrÖDER, W., and Francke, W. 1990. Volatile cephalic secretions of drones, queens and workers in relation to reproduction in the stingless bee, Scaptotrigona postica (Hymenoptera: Apidae: Trigonini). Entomol. Gener. 15:91-101.

Engels, W., Engels, E., and Francke, W. 1997. Ontogeny of cephalic volatile patterns in queens and mating biology of the neotropical stingless bee, Scaptotrigona postica. Inverteb. Reprod. Develop. 30:251-256.

FrancKe, W., and SchulZ, S. 1999. Pheromones, pp. 197-261, in S. D. Barton, and K. Nakanishi (eds.). Comprehensive Natural Products Chemistry, Vol. 8. Elsevier, Amsterdam.

IVANOV, V. D. 1985. Behavior of caddisflies in flight. Latvijas Entomologs. 28:85-94, (In Russian).

IVANOV, V. D. 1992. Evolution of flight of caddisflies, pp. 351-357, in C. Tomaszewski (ed.). Proc. of 6th Int. Symp. on Trichoptera, Adam Mickiewicz University Press, Lodz.

IVANOV, V. D. 1993. Principles of the sexual communication in caddisflies (Insecta, Trichoptera), Sensory Systems of Arthropods. pp. 609-626, in K. Wiese et al. (eds.). Birkhäuser Verlag, Basel.

IVANOV, V. D. 1994. Vibratory signalling in caddisflies (Insecta, Trichoptera). Zool. Zhurnal. 73:55-70, In Russian.

Kelner-Pillault, S. 1975. Attirance sexuelle chez un Trichoptère: Enoicyla pusilla Burmeister. Bull. Soc. Entomol. Fr 80:252-257.

KJer, K. M., Blahnik, R. J., and Holzenthal, R. W. 2002. Phylogeny of caddisflies (Insecta, Trichoptera). Zool. Scr. 31:83-91.

Kozlov, M. V., Zhu, J., PhilipP, P., Francke, W., Zvereva, E. L., HANSSON, B. S., and LÖFSTEDT, C. 1996. Pheromone specificity in Eriocrania semipurpurella (Stephens) and E. sangii (Wood) (Lepidoptera: Eriocraniidae) based on chirality of semiochemicals. J. Chem. Ecol. 22:431-454.

LARSSON, M. C., and HANSSON, B. S. 1998. Receptor neuron responses to potential sex pheromone components in the caddisfly Rhyacophila nubila (Trichoptera: Rhyacophilidae). J. Insect Physiol. 44:189-196.

larsson, M. C., Hallberg, E., Kozlov, M. V., Francke, W., HANSSON, B. S., and LÖFSTEDT, C. 2002. Specialized olfactory receptor neurons mediating intra- and interspecific chemical communication in leafminer moths Eriocrania spp. (Lepidoptera: Eriocraniidae). J. Exp. Biol. 205:989-998.

Löfstedt, C., Hansson, B. S., Petersson, E., Valeur, P., and RichARDS, A. 1994. Pheromonal secretions from glands on the 5th abdominal sternite of hydropsychid and rhyacophilid caddisflies (Trichoptera). J. Chem. Ecol. 20:153-170.

LÖFSTEDT, C., and KozLOv, M. 1996. A phylogenetic analysis of pheromone communication in primitive moths, pp. 473-489, in R.T. Cardé, and A.K. Minks (eds.). Insect Pheromone Research: New Directions, Chapman \& Hall, New York. 
MClafferty, F. W., and Stauffer, D. B. 1989. The Wiley/NBS Registry of Mass Spectral Data. Wiley, New York.

MorSE, J. C. 1997. Checklist of world Trichoptera, pp. 339-342 in R.W. Holzenthal, and O.S. Flint, Jr. (eds.). Proc. 8th Int. Symp. Trichoptera. Columbus, OH: Ohio Biological Survey.

Morse, J. C., editor. 1999. Trichoptera World Checklist. http:// entweb.clemson.edu/database/trichopt/index.htm, effective 22 May 1999, updated 28 July 2000, 8 January 2001, December 6, 2006.

Morse, J. C. 2003. Trichoptera (Caddisflies), pp. 1145-1151, in V. H. Resh, and R. T. Carde (eds.). Encyclopedia of Insects. Elsevier.

Petersson, E., and Solem, J. O. 1987. Male mate recognition in Leptoceridae, pp. 157-160, in M. Bournaud, and H. Tachet (eds.). Proc. 5th Int. Symp. Trichoptera. Dr. W. Junk Publishers, Dordrecht

RESH, V. H., JACKSON, J. K., and WoOD, J. R. 1987. Techniques for demonstrating sex pheromones in Trichoptera, pp. 161-164, in M. Bournaud, and H. Tachet (eds.). Proc. 5th Int. Symp. on Trichoptera. Dr. W. Junk Publishers, Dordrecht.

RESH, V. H., and WoOD, J. R. 1985. Site of sex pheromone production in three species of Trichoptera. Aquat. Insects 7:65-71.

Ross, H. H. 1964. Evolution of caddis worm cases and nets. Am. Zool 4:209-220.
SOLEM, J. O. 1984. Adult behavior of north European caddisflies, pp. 375-382, in J. C. Morse (ed.). Proc. 4th Int. Symp. Trichoptera. Series Entomologica, 30. Dr. W. Junk Publishers, The Hague.

SolEM, J. O. 1985. Female sex pheromones in Rhyacophila nubila (Zetterstedt) (Trichoptera, Rhyacophilidae) and arrival pattern to sticky traps. Fauna Norv. Ser. B. 32:80-82.

Solem, J. O., and Petersson, E. 1987. Demonstration of female sex pheromones and adult behavior in Molanna angustata (Trichoptera: Molannidae). Entomol. Gen. 12:115-118.

Tóth, M., SzÖcs, G., Nieukerken, E. J., VAN, PhilipP, P., Schmidt, F., and FrANCKE, W. 1995. Novel type of sex pheromone structure identified from Stigmella malella (Stainton) (Lepidoptera: Nepticulidae). J. Chem. Ecol. 21:13-27.

WeAVER, J. S. 1984. Evolution and classification of Trichoptera, part I: Groundplan of Trichoptera, pp. 413-419, in J.C. Morse (ed.). Proc. 4th Int. Symp. Trichoptera. Series Entomologica, 30. Dr. W. Junk Publishers, The Hague.

WooD, J. R., and RESH, V. H. 1984. Demonstration of sex pheromones in caddisflies (Trichoptera). J. Chem. Ecol. 10:171-175.

Zhu, J., Kozlov, M. V., PhilipP, P., Francke, W., and Löfstedt, C. 1995. Identification of a novel moth sex pheromone in Eriocrania cicatricella (Zett.) (Lepidoptera: Eriocraniidae) and its phylogenetic implications. J. Chem. Ecol. 21:29-43. 